
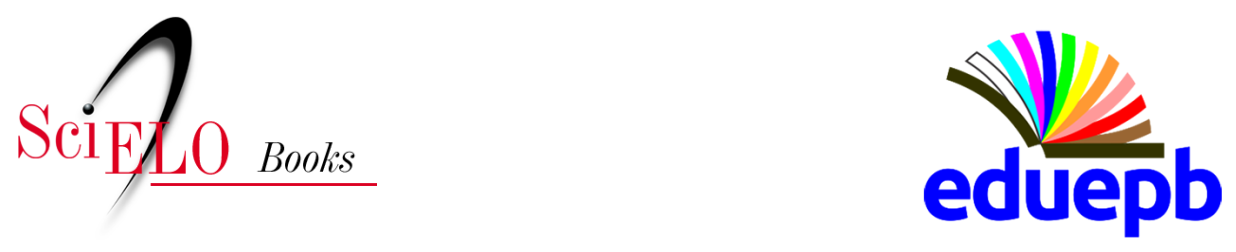

\title{
Reinstating Institutions The Return of Natural Philosophy in Times of Academic Postmodernity
}

\author{
André L. de O. Mendonça \\ Antonio A. P. Videira
}

\section{SciELO Books / SciELO Livros / SciELO Libros}

MENDONÇA, A. L. O., and VIDEIRA, A. A. P. Reinstating Institutions: The Return of Natural Philosophy in Times of Academic Postmodernity. In: SILVA, A. P. B., and MOURA, B. A., eds. Objetivos humanísticos, conteúdos científicos: contribuições da história e da filosofia da Ciência para o ensino de Ciências [online]. Campina Grande: EDUEPB, 2019, pp. 357-380. ISBN: 978-85-78795-79-5.

http://doi.org/10.7476/9786586221664.0012.

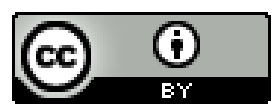

All the contents of this work, except where otherwise noted, is licensed under a Creative Commons Attribution 4.0 International license.

Todo o conteúdo deste trabalho, exceto quando houver ressalva, é publicado sob a licença Creative Commons Atribição 4.0.

Todo el contenido de esta obra, excepto donde se indique lo contrario, está bajo licencia de la licencia Creative Commons Reconocimento 4.0. 


\title{
REINSTATING INSTITUTIONS: THE RETURN OF NATURAL PHILOSOPHY IN TIMES OF ACADEMIC POSTMODERNITY99
}

\author{
André L. de O. Mendonça (IMS/UERJ) \\ alomendonca@gmail.com

\section{Antonio A. P. Videira (IFCH/UERJ) \\ guto@cbpf.br}

\section{Introduction}

While the meta-narrative presented by Kuhn may have been restricted to analyzing the natural sciences, it has been extrapolated to other areas by sociologists, psychologists, philosophers, and others, often with the aim of problematizing their respective scientific statutes, giving rise to new perspectives in these disciplines. Compared to philosophy and sociology, history has arguably undergone more transformations. As for the history of science, it would not be an overstatement to talk in terms of B.K. (before Kuhn) and A.K. (after Kuhn).

99 An expanded version (in Portuguese) of this article will be published in: MINHOT, LETICIA; DIAAS, EVA MORENO (Eds.) Representaciones. Revista de Estudios sobre Representaciones en Arte, Ciencia y Filosofía. v.14. n.1. 2018. Sirca Publicaciones. ISSN 1669-8401. Edición especial, editoras Leticia Minhot, Eva Moreno Días. AAPV thanks CNPq for the grant $n^{\circ}$ 30495/2014-5 and FAPERJ for the fellowship Prociência. 
There is no shortage of appropriations, primarily of Kuhn's controversial and polysemous concept of "paradigm," in the social sciences and humanities. In fact, there have been all manner of attempts to employ his methodological and theoretical framework to understand the nature, development, and scope of numerous areas of knowledge. For those who are familiar with the sometimes harsh criticisms levelled at Kuhn over the three decades of his involvement in the history and philosophy of science, it seems somewhat ironic that his theoretical framework was incorporated by "humanistic" culture. Could this be an indicator that, deep down, the natural and social sciences are not "naturally" distinct from one another, or, to put it differently, that Kuhn's great contribution was to show that the "Two Cultures" were actually both culturally conditioned? Despite the importance of this question, the general relationship between Kuhn's ideas and the social sciences and humanities, in terms of ascertaining whether there is, indeed, such a difference between the Two Cultures, is a topic - however worthy of discussion - that falls outside the scope of this paper. Instead, our aim here is, on our own terms (meaning, respecting our condition as inhabitants of Latin America), to reframe the subsequent ramifications of the historiographical and philosophical framework Kuhn used to shape his image of science as they have appeared in the new history of science and in science studies ${ }^{100}$. In other words, we shall focus on studies that are normally geared towards the natural or exact sciences, drawing on their own "empirical" methods.

Taking Lorraine Daston's essay "Science Studies and History of Science" as a leitmotiv, we put forward a thesis in favor of creative and reflective syntheses of the great quantity of fragmented and scattered empirical material produced by the new history of science, provided these syntheses respect our Latin Americanness,

100 For a discussion of Kuhn's legacy, as disputed in the new history of science and science studies, from the perspective of the persistent asymmetry between facts and values, see Mendonça and Videira (2013). 
which in our view implies rejecting the proposal made by Daston. Sensing, as it were, a whiff of nostalgia for modernity in the air, we want to rethink the "negative" role recently attributed to great narratives, reinstating their lost dignity, but without in so doing setting out in search of some bygone era of Essentialist Foundationalism ${ }^{101}$. In order to develop our argument as clearly and coherently as possible, our ideas are organized into the following sections: 1 - a schematic reconstruction of the theoretical assumptions behind today's social historiography of science; $2-$ a critical discussion of Daston's aforementioned essay; 3- a presentation of the problems that hamper attempts to incorporate Daston's dilemma into the reality found in countries like Brazil, in view of the conditions under which their scientific institutions exist. In other words, how we should go about harnessing philosophy for a "return to the era of the great narratives" in peripheral countries. The main barrier to this is the state of their institutions, particularly the ones engaged in science.

\section{A Brief History of the History of Science}

When it is analyzed from the perspective of its current status, there seems to be a widespread feeling that the history of science is going through a period of conceptual and methodological transformation. For some historians and philosophers of science, these transformations are better characterized as difficulties. Or, to put it differently, even today there are still questions about its "real" objectives or the right methods for attaining them. This state of affairs forces practically any and all historian of science

101 Without failing to acknowledge the importance of the approach itself, we take an opposing position, therefore, to the position taken by those who defend a "local philosophy of science." Reflecting on the political and epistemological implications of this branch, Mendonça (2013) makes a critical analysis of the thinking of Joseph Rouse. 
today to call into question the aim of the history of science and the importance of his/her activity. One of the reasons why such questioning is so necessary is the rapid and widespread growth of this discipline, as witnessed by the great number of journals and books published, conferences, colloquia and symposiums held, and national and international societies devoted to the history of science. Yet this rapid growth should not be construed as meaning that the history of science is a newcomer to the field of human intellectual endeavour. Actually, it is old.

This "old age" of the history of science seems to have caused it serious difficulties, since it does not have a single definition. The lack of consensus about how to define the history of science became evident as of the 1960s, when Thomas Kuhn's wellknown work The Structure of Scientific Revolutions elicited such strong reactions. Without a consensual definition, the history of science found itself mired in a crisis of identity.

This crisis could be seen as stemming from a tension between at least two different ways of approaching the history of science. First, there is the way scientists themselves, protagonists of science, approach the history of science after migrating (for whatever reason) from actor to author. When this is the case, the historiographical genres of choice tend to be histories of disciplines and scientific autobiographies. There is a well-known thesis that scientists only start worrying about the history of science when they retire-basically motivated by a concern to have their names and achievements recorded in the history books of their respective fields of expertise (RUSSELL, 1948, p.777). Scientists, at least in the eyes of professional historians, write history in order to legitimize their own conceptions and ideas. This quest for legitimacy could result in the ideas, ideals, and methods of science being applied outside its domain, constituting a case of scientism ${ }^{102}$.

102 For more on the historiography of scientism, see Hakfoort (1995). 
A different historiographical perspective is taken by historians and sociologists, who regard themselves as far more critical towards the values conveyed and advocated by scientists. They see scientists as being unmoved by any concern or interest beyond the understanding of how science has developed. For scientists, it would be unacceptable to give the history of science the right or opportunity to legitimize science. Their opponents argue that such legitimization presupposes a problematic image of science that is anachronistic, presentist, and shaped by the interests of individuals or groups, just to cite a few of the "defects" of the scientist historiography of science.

Awareness of these complications in the history of science seems to have first been awakened in the early 1930s. Not only is it an ancillary science, but it has been dogged by this secondary or auxiliary status since its very inception. Going back to the seventeenth century, the history of science has always been used for purposes outside its realm. However, this surely begs a question: Did anybody know what the true goals of the history of science where when it first emerged? Would it not have been too early to formulate such a question? What could have prevented the history of science from being used for "purposes other than its own"?

The conception of the history of science as an ancillary discipline, insofar as it legitimizes certain practices, is evident in the type of history produced by scientists. The genre of history to which they devote their energies could be labelled a "history of problems." In fact, it is a type of history that could be given several names. Its main problem stems from the fact that it is hard for this genre of historiography to be unteleological, in that it leads (always as naturally-sounding as possible) to the current solution for the problem, or at least to the point its resolution had reached at the time the story was told. In other words, the final destination of conceptual history is the present day. If the historical description leads us to the scientific solution now held 
as valid, it can be deemed satisfactory and successful in explaining the development of that bit of science.

We have to assess what goals and interests are at play when history of science narratives are formulated; after all, it would be misguided to imagine that the history of science is unbiased. Indeed, it is built on certain values and theses about the nature of science and about the objectives attributable to the history of science. These values and theses, which constitute images of science and its goals, should be analyzed explicitly to get to the root of the historical narrative. It would therefore be naive to think that the history of science is objective just because it corresponds to a set of facts that have the capacity to impose themselves incontrovertibly on historians ${ }^{103}$. Essentially, the history of science's identity problem derives from the controversies surrounding the suggested answers to two questions: What is history of science? and What is its goal? Or, quite simply: Why engage in the history of science?

Even if reaching a consensual characterization or definition of the history of science is no easy or straightforward matter, its historical evolution can still be understood in general terms. One of the ways of doing so is to analyze the writings (books, papers, articles) produced in the area. If studying the literature is the right "path" for understanding how the history of science has developed, then the most accurate description of this activity would be the study of the history of the historiography of science. By examining the sequence, growth, and proliferation of historical writings about science, it is feasible to reconstitute a meaning for the lineage and formation of the history of science as an autonomous field of inquiry governed by academic standards.

103 The very choice of facts and protagonists to be included in the history to be told already establishes a relationship with the image of science. They are chosen (and essentially come into existence) because of it. 
The history of the historiography of science can shed light on the trajectory of the disciplinarization of the history of science.

Generally speaking, when reference is made to historiography, one first thinks of a critical analysis of published works about the history of science. Such a critical analysis is generally designed to comprehend three points in particular:

1) On what conception (or image) of science did the historian base his/her historical narrative?

2) What questions does the historian regard as important and therefore worth answering?

3) What are his/her goals in attempting to answer these questions?

These questions could be supplemented by at least one more, which is gaining ground at the present time: What readership (or audience) does the science historian address? Or, indeed, what audience "consumes" the history of science? The growing relevance of this question can be explained essentially by two factors. The first has to do with the fact that some of the reasons proposed in the twentieth century (as detailed below in our discussion of Daston's ideas) to justify the institutionalization of the history of science are now being reassessed. The second, related to the first, has to do with science itself, which, after the Second World War, was the target of harsh criticism from all segments of society. For many scientists and science administrators, the history of science would have the power to explain and legitimize, albeit in general terms, some of the main characteristics of science. Before this time, the prevailing school of thought was that the history of science exemplified important philosophical theses, like belief in scientific progress, almost invariably viewed as linear and cumulative.

One of the origins of the social history of science was skepticism about the widely held thesis that the development of science would inevitably lead to progress, happiness, and the material 
and spiritual wellbeing of humankind ${ }^{104}$. This skepticism gradually took root across the world after the two world wars in the first half of the twentieth century. In their wake, science could no longer be held up as a surefire source of happiness whose only concern was understanding and harnessing the natural world for the benefit of humans. Holding a position like this, also known as a scientific mentality, came to be seen as naive.

As of the mid-twentieth century, the idea that science was not neutral gained currency, albeit not without opposition from some scientists and pro-science philosophers. It was held that science and scientists were motivated by interests other than just the acquisition of knowledge about nature and the furthering of human wellbeing. The fact that science played an important role in the development of military might and proved incapable of answering the very questions it posed prompted mistrust towards the cognitive capacity and axiological neutrality of science.

The involvement of science in the planning and development of new weapons, its growing conceptual complexity, the apparently endless march of technological progress, science's insatiable thirst for financial resources, and its increasing incomprehensibility to the layperson and even other scientists made science a cause of fear and repulsion. Understanding what science was and how it was done was no longer self-evident. Such difficulties-already present in the discourses of philosophers and even of scientists concerned about the determination of the nature of science and its methods of investigation and justification-led to the explicit recognition, as shown by the celebrated work by C. P. Snow, The Two Cultures, that there was an ever widening chasm between science and the rest of human society.

104 The "social history of science" is not very precise and does not translate exactly our ideas about the historiography of science in practice today. Nonetheless, in the absence of a better-known expression, this is the one we will use, albeit recognizing its theoretical shortcomings. 
This gap continues to be a major problem today, at least if we take a look at the existing literature. After all, since the mid-seventeenth century, most western societies have been organized around science. Three centuries since the emergence of "modern science," there is again a pressing and inescapable need to legitimize science and bring it closer to non-scientists, who nonetheless need it for their survival - i.e. virtually the entire population of the world. One way of stopping the gap between scientific and non-scientific culture from growing would be to understand how science developed from the seventeenth to the twentieth century. In other words, for science to overcome the post-war wave of pessimism, it is important to know what it once was and how it acquired such a pivotal role in western civilization.

One person who cannot be ignored in any investigation of the institutionalization of the history of science in the USA designed to bridge this gap between science and society is the American chemist James Conant, who, in the 1950s, set up a history of science program to refresh and renew the teaching of science. One "offspring" of this program was Thomas Kuhn, as he himself acknowledges in the foreword to The Structure of Scientific Revolutions. It is curious that in the United States, the history of science attained its current-day proportions thanks to a decision taken in a sphere that, while certainly being cultural and academic, was nonetheless clearly intended to allow its effects to spread beyond the bounds of academia and higher education. In other words, the scale of the support given to the history of science today only makes sense when one sees that it met a need felt outside the walls of academia, that it was in the interests of furthering scientific education in the country and the advocacy of science for the population as a whole. This movement, sponsored by Conant, helped speed up the institutionalization of the history of science. From then on, the history of science started to run at two different tempos: the pace of its institutionalization and the pace of the development of its disciplinary bedrock. 
Earlier, we stated that one of the jobs of the history of science is to understand the most important characteristics of the image of science, as expressed, for instance, in the output of a scientist. It is necessary to observe that by "characteristics" we mean the epistemological and methodological principles and values defended and effectively used by scientists. According to Conant, this clarification helps facilitate the comprehension of scientific content and helps people from outside the world of science to understand its true value. In other words, the history of science is responsible for making science less foreign and distant to the lay public. But it is not enough merely to clarify the characteristics of the image of science now, as described by scientists. For historians to fulfilll their task, they must also have an image of science at their disposal. While many present-day science historians do not subscribe to this view, holding that it establishes an asymmetrical relationship between history and the philosophy of science, this is not a position we share, as it is not possible to talk about something without being able to recognize it. This concern should not, however, be overstated, otherwise it could make the history of science an overly technical domain, to the point of being of interest only to those engage in it professionally. This seems to be the conclusion drawn by Lorraine Daston, whose thinking we shall investigate in the next section.

\section{The Victory of Mediocrity: the Professionalization of the History of Science}

Drawing on the ideas in Sheila Jasanoff's (2000) paper on the relationship between science studies and the history of science (a kind of lament about their mutual distance), Lorraine Daston suggests there is "a more general pattern in the relation between disciplines and interdisciplinary clusters that address the same matter-in this case, science and technology" (2009, p.798-99) -and that one discipline will normally look down on 
any other that wants to draw closer to it, while at the same time making overtures to another discipline that is indifferent to it. Her central argument is that the root of the divergence between science studies and history of science since the mid-1990s lies in their different conceptions of science, which, she argues, led to their mutual distancing. Ignoring for now the imprecisions stemming from the avowedly "maddeningly tendentious" nature of her account in favor of the history of science, it is worth sketching out Daston's narrative here, which she herself admits is no more than a general outline. Our initial assumption is that her reflections are of the utmost importance to anybody keen to work in science studies or history of science in a genuinely proficuous manner in the coming years.

After mentioning the more remote, oft-forgotten lineage of science studies (a veritable academic cultural melting pot, ranging from the socialist spectrum to the liberal: Durkheim, Marx, Mannheim, Bernal, Wittgenstein, Polanyi, Fleck, and others), Daston refers to the text that, like it or not, essentially forms the starting point for both fields: Kuhn's groundbreaking The Structure of Scientific Revolutions, written over fifty years ago. ${ }^{105}$ As Daston puts it, this is a work that was interpreted in one way by the history of science and in another by science studies: as anti-Whig history (contextualization) and as relativist manifesto (symmetry principle), respectively. However, these distinct receptions of Kuhn's work were initially overlooked, for reasons that included the existence of a shared enemy (positivism) and a concern with greater integration between science and society, not to mention the importance of the role played by three categories of analysis central to both fields: contingency, negotiation, and work (agency).

105 Mendonça (2012) reflects on Kuhn's legacy on the 50th anniversary of The Structure of Scientific Revolutions. 
Despite these promising beginnings, science studies and the history of science began to diverge from one another more recently because of increasingly intractable differences in their respective positions of "estrangement" towards science: while science studies practitioners drew on symmetry as a kind of sociological suspicion, as exemplified by expressions like "social construction," historians of science called on contextualization as historical understanding. More serious still: however unlikely it may seem, science studies take science as a given, while history of science considers scientific practices as the explanandum. This could be because advocates of the former are keen to make science transparent to society, unlike their science historian counterparts, who are "only" interested in understanding what science is and how it works in concrete terms, or, to borrow the words of Daston, "accurate historical reconstructions." In this sense, the history of science has indubitably veered towards narratives, increasingly located in time and space, about materially conditioned scientific practices. Strictly speaking, as Daston argues, what the historicist history of science intends to do is find out how knowledge forged locally is turned into "universal science" through a negotiated and contingent process.

Curiously, for Daston, the two advantages of the history of science over science studies - without nourishing any sociological suspicion toward science or considering generalizations relating to science - are actually corollaries of its recent disciplinarization in closer alliance with history (its adoption by historians). Thanks to its inclusion in the discipline of history, the history of science has learnt to avoid the anachronism and teleology still prevalent in other fields. Obviously, as Daston herself points out, the great number of microhistories of a truly historical bent produced by the history of science is, paradoxically, a concrete expression of the stated aim of science studies to pay attention to context and practice: "Simply put, the more historical the history of science became the less the science it studied resembled the prepackaged 
subject matter of science studies" (DASTON, 2009, p.810-11). Essentially, Daston's thesis is that the history of science has been more successful than science studies in seeking out a more appropriate understanding of science in virtue of its having molded itself as a discipline along the same lines as history itself, even if it does not yet attract the unreserved recognition of historians. However, recognizing that in life there is always a price to pay, Daston (2009, p.811) herself adds a footnote in which she sets forth the pros and cons of these less eclectic, more miniaturizing narratives.

Although she demonstrates a certain enthusiasm for the new images of science contained in the detailed accounts of the new historicist history of science, Daston seems to hark back nostalgically to its pre-disciplinarized past, or, to be more precise, expresses concern with the predominance of mediocrity. Indeed, at the end of her work, she calls on readers to propose a new type of interdisciplinarity in order to synthesize or combine the wealth of material that is so fragmented in these new narratives: "Philosophy, anyone ${ }^{106}$ ?"

Although it is an evaluation paper, Lorraine Daston's "Science Studies and History of Science" does not state a clear position about the relations - once friendly, now indifferent at best - between the practitioners of science studies and the history

106 At the end of the introduction to his book Never Pure, Steven Shapin (2013) states that his work and that of other science historians was to have lowered the tone: "It would be easier to maintain that commitment - to richness, to detail, to accuracy - if we felt that we were doing God's work, but it's more admirable, I think, if we feel that same commitment, that same sense of vocation, when we know that we are not on a divine mission. That we are telling stories - rich, detailed, and, we hope, accurate - about a tone-lowered, heterogeneous, historically situated, embodied, and thoroughly human set of practices. That is, when we are doing what now counts as the history of science" (p. 14). However much we may identify with the stories Shapin tells, perhaps he himself does not extract due inferences from his own work; after all, is the only alternative to divine grandeur human smallness? 
of science. At the end of the day, is she pro-science studies or pro-history of science, or would she rather they interacted with one another? If this last option is true, what does she see such dialogue achieving? Is she interested in buttressing the position of history of science not so much against science studies, but vis-à-vis other scientific disciplines? Might she be favourable to embedding science studies in the history of science? She could have indicated where she stands on this point if she had been more decisive in stating the advantages already garnered by science studies and the history of science when they still interacted. Nonetheless, despite certain significant gray areas, we do not feel the need to adopt the common posture in philosophy of destroying the work under discussion before progressing towards our own propositions.

\section{The Return of Natural Philosophy: Beyond Bureaucratization}

As we see it, the basis of our reflections should be as follows: What is the point of carrying on doing science? In other words, if we are to carry on doing science based on our present-day targets or goals (almost all of which are technological or applied), do we still need scientists? This problem lies at the heart of some reflections proposed by certain figures who have flirted with science studies, like John Ziman (1999). He predicted that the scientist, as he understood him to be, would be completely dispensable in the model of the scientific organization that began to prevail after the Second World War.

If science studies acritically accepts the view of science as it was proposed and spread throughout the twentieth century, this leads to an apparently irrefutable conclusion that science studies intends to do nothing more than reform this science.

If we put together the statements in the two preceding paragraphs, we are left in the following predicament: even though 
science studies came into being with the intention of bringing science and society closer to one another and this has in fact come about, the price has been very high. Science has become an integral part of society (as witnessed by all the science and technology ministries, funding agencies, and science columns in daily newspapers), but in the process it has been bureaucratized.

However, the traditional ethos of the scientist does not lie well with this bureaucratization. Scientific discovery cannot be pursued in an environment of officialdom where routine reigns supreme. In other words, the official and government-sponsored support and communication of science has done it harm, just like the British "conservatives" predicted in the first half of the nineteenth century. If we are right on this point, it could be argued that Daston is harking nostalgically back to the time when science studies and history of science were not official or professionalized. By invoking philosophy, might she not actually be thinking (as we, indeed, are) that philosophy is something that cannot be professionalized or bureaucratized or completely institutionalized? If this is the case, alongside the intrinsic "polyglotism" of philosophy, it has another advantage: insurgency. By its very nature, it is immune to rules imposed from outside.

The problems raised by people like Ziman were somewhat hidden from view under the "Humboldtian" model of higher education, which prevailed until the mid-twentieth century. Until then, the building blocks of universities were their faculties of philosophy and their different professional schools, which were separate from the former. After departments and institutes were created in the name of efficiency, it could no longer be denied that science had become routine practice. Does that mean, then, that philosophy should speak out against the way science is now done? If this is what Daston is calling for, then philosophy will stand against science studies. 
This leads to the inevitable conclusion that, for Daston, philosophy is, first and foremost, dialogue. And this dialogue, at least to start with, should be impartial, since its starting point is external to it. Another feature of philosophy that constantly appears in Daston's paper is its independence from theses. In other words, philosophy does not have theses of its own that it defends against all-comers. Daston therefore seems to accept an Enlightenment conception of philosophy, where its only role is criticism.

We do not agree that a critical function alone is enough to bring philosophy back to its rightful place for dialogue, even if it is between science studies and the history of science. As Galileo already believed, the most important dialogue is our dialogue with nature (which includes human nature). Entering into dialogue with nature implies wishing to know what it is and how it behaves. Without intending to do any mental backflips, we would hold that philosophy should move closer to natural philosophy as it existed until the beginning of the nineteenth century. In other words, philosophy should once again concern itself with discovering what reality (including human reality) is. But how, if at all, can this take place?

The final question Daston formulates should be answered thus: Philosophy would be capable of finding a principle that was general enough for the history of science to tell a great narrative about science. Neither the history of science nor science studies has been able to encounter this "principle." Arguably, it would run counter to the very idea of science studies, which generally stands against all and any unified image of science. However, the same could be said of a history of science that rejects teleology and presentism. But what is to be gained by piecing together a great narrative of science? Is there some "common enemy" out to get science studies and the history of science? Is it relativism or pluralism? Maybe it is. Relativism is the natural philosophical position for whoever turns to science through the lens of the 
history of science and science studies. It is a philosophical position that is embedded in the image of science proposed by both areas. Thus, relativism (or pluralism), science studies, the history of science, and science inhabit the same universe. They are like beings in a two-dimensional planet: to see the whole (or totality), one would have to find a structure capable of shifting away from this "universe". Maybe this is the role Daston would attribute to philosophy.

But could philosophy fulfill this role in Latin American academic institutions? We would hesitate to give a positive reply. In these settings-and bearing in mind that doing science means doing scientific politics-philosophy is not one of the elements normally called on to design science development policies, which weakens and debilitates it.

\section{Reinstating Institutions}

Since modern science consolidated the features and characteristics for which it has become known, the role of scientific institutions has been recognized. It is acknowledged that the institutions of science - its societies, journals, academic curricula, etc. - have contributed significantly both to the emergence of modern science and to its process of consolidation. What is not clear - and has sparked controversy amongst scientists, philosophers, sociologists, and historians - is what esteem or value these institutions are owed. For instance, does it make any sense to imagine that modern science would not exist without the institutions that harbor it? This seems to be John Ziman's conclusion. Whether it would or not, this question does not exhaust the topic. Could science have emerged without the institutions it is represented by? Paolo Rossi (1999), for instance, sees modern science as emerging in Europe outside the walls of its medieval universities. 
In order for universities to contribute to the consolidation of science, they had to change, putting many of their medieval characteristics behind them. The changes universities had to undergo to meet the needs of modern science began in the late 1700s and early 1800s, gaining particular contours in the reform of the University of Berlin in 1810. Ever since then, teaching and research have been indissociable: researchers (who wish to augment the sum of human knowledge) must teach and teachers (who are familiar with the latest discoveries in the scope of human knowledge, and who may or may not have contributed to some discovery) must do research. Despite the current-day validity of this bilateral relationship, it suffers (and has indeed suffered almost since it was introduced) from pressures of all kinds, especially questionings about its real effectiveness for the production of novelties. Essentially, there is a not insignificant body of scientists who feel that teaching "diverts" them from their "mission" to discover new truths about nature.

In the last century, scientific institutions became an incontestable fact of life, even while those who defended the university model accepted that a gamut of different institutions should coexist alongside them, including technical universities, research institutes, academies, etc. The Humboldtian model ceased to be the only or even the best option. One figure who stands out amongst those who foretold the end of the German university model was Max Weber, who in 1917, on the invitation of Bavarian students, gave a talk that still reverberates today entitled "Science as a Vocation."

In the countries where modern science arrived "late," this replacement of the prevailing model did not happen, either because they did not have any universities when they were colonies (a prime example being Brazil) or because the universities founded under colonial rule did not cater to modern science (which seems to have been the case in the former Spanish colonies). In these 
countries, whatever empire they belonged to, an education and research system that was varied and plural had to be created. In other words, just when they were introducing "modern" universities along the lines of the pre-existing models in Europe and the United States, they were also having to tackle the problems these institutions were now afflicted by. Their new universities were created with the same handicaps that existed elsewhere, where they had been around far longer. This seems to have hampered the whole process. Stages, it was then thought, would have to be leapfrogged or quickly traversed for these countries (e.g., in Latin America) to produce science up to "international" standards and for competent experts to be educated and employed in different sectors of their respective societies. Meanwhile, when the universities were created, the "scientists" from these countries, most of whom had trained at professional schools (of engineering, medicine, or law) that had existed since the early nineteenth century or even earlier, knew they were not up to the task of teaching or researching to the required standard. Young people would have to be sent abroad to be trained at more "advanced" centers of academia in order to acquire the knowledge they needed to fulfill their tasks to the expected level. This local "backwardness" was a determinant - or rather, an obstacle - that had to be taken into consideration.

"Modern" education and research systems were eventually formed, especially in the second half of the twentieth century. Since then, the idea that science is important not just for economic development, but also for national security, has become entrenched around the world. During the decolonization of Africa and Asia, a process marked by the notion of national independence, science and its applications were understood as being a prerequisite for obtaining independence or political autonomy or even complete sovereignty. Science was a "natural" part of the political game. Politicians had to try to comprehend what science 
was, and did so with varying degrees of success. The multiplicity of actors engaged in science had certain effects that should not be ignored. Here, we will focus on just one of them; namely, the inclusion of different values relating to the nature of science and its importance to society. The values that were effectively adopted were not just the ones that scientists attributed to science. These values had to vie with others, some of which were explicitly rejected by the practitioners of science, since they were championed by persons who were "alien" to the academic world.

In the case of a country like Brazil, during the initial stages of creation and organization of the education and research system, scientists particularly accentuated the value of "pure" science, albeit without overlooking the importance of applied science, knowing as they did that it was a more effective tool of political persuasion. Two names worth mentioning to illustrate this point, again from Brazil, are Henrique Morize and Manoel Amoroso Costa. Amoroso Costa published an article in a former Rio newspaper, O Jornal, entitled "For Pure Science" (VIDEIRA, 2003).

The considerations we have set forth so far enable certain preliminary conclusions to be drawn. Higher education institutions that also support science are not stable structures, but dynamic. Transformation is inherent to their nature. What often disturbs the people working in them is the type of transformation they go through and the reason for such transformation. When external pressure (from national governments, the armed forces, industrial conglomerates, etc.) is strong, to the point of upsetting their balance, university "inhabitants" rise up in protest and proclaim their autonomy, the right to decide what and how they should change. Nonetheless, it must be acknowledged that scientists and academics are often slow to react to demands from the "outside world". And maybe they are right. If the fundamental reason for joining and remaining in the university world is vocation, it follows that scientists are better placed to decide what and 
how to change. However, if the system of research and education is actually designed to train professionals, the "outside world", or society, must have a determining influence. Perhaps this is why even today, professional schools (of engineering, medicine, law, nursing, accountancy, economics, etc.) do not just continue to survive, but actually thrive.

Just like science, the education and research system is not uniform, but fragmented. We should not forget that Wilhelm Humboldt never finished his text, leaving it without a conclusion precisely when it should address the relationship between universities and research institutes. "What are universities for?" is an ever-relevant question. And it seems to be one that cannot be ignored, as if the question of purpose were perennial when it comes to the university. As a rule, it is understood as implying that universities are in a constant state of crisis, as if crises were a constant in the life of universities, wherever they are. This seems not unreasonable, in that science itself is in a constant state of flux.

The first universities in Brazil were founded in the 1930s and were based, at least on paper, on the Humboldtian model. However, the faculties of philosophy at the University of São Paulo and the University of Brazil (in Rio de Janeiro), the two main universities until the higher education reform in the late 1960s, were unable to assure science a solid footing, since several prerequisites were missing, such as adequate pay, laboratories, up-to-date libraries, opportunities for exchange with more advanced institutions, graduate level education, and more.

Prior to the 1930s, all attempts to change Brazil's education and research system had been half-hearted. This is due in part to the fact that education and research were left out of all nation-building endeavors devised until then. The relationship between science and nation building changed when Getúlio Vargas rose to power in 1930, and then again, more significantly, after the Second World War. As of the 1930s, Brazilian scientists 
supported moderate nationalism, without military or conservative excesses. Science was an integral part of a world view keen to promote the country's social, economic, and cultural development.

While it would seem beyond question that the Brazilian higher education and research system has grown, matured, and spawned significant scientific results, the price of these achievements is perceived as being too high. In line with global trends, scientists have become hostages of government funding. In a country like Brazil, where there is virtually no private investment, handouts from government agencies (e.g. CNPq and CAPES) are the primary sources of resources. The money is distributed through public calls for projects, which themselves induce what research is to be done. In recent years, these calls for projects, mirroring a "conclusion" now apparently taken for granted, have focused primarily on promoting innovation. In other words, they aim to harness science to add economic value to products exported by Brazil. The results of this bid to boost innovation have so far failed to live up to expectations.

There are no robust questions being asked about what science should be used to achieve. Notions of progress, for instance, seem to be based on the same ideas that have dominated European nations since the nineteenth century. This automatic acceptance of the values that determine and configure science means the prevailing conception of science is imported ready-made and taken on board without due criticism or reflection. Science is accepted as a universal "thing". And if this is the case, how can anyone expect philosophy to be an "instrument" of transformation, as Daston urges?

If there is indeed any chance of changing science in Latin America, this change will probably not be prompted by any contribution from the field of philosophy. But what about the history of science? Perhaps. After all, the history of science we see around us seems concerned with recuperating political and social ideas 
not only of scientists, but also of intellectuals and members of groups often seen as excluded.

\section{References}

DASTON, L. Science studies and the history of science, Critical Inquiry, v.35, n.4, p.798-813, 2009.

HAKFOORT, C. The historiography of scientism: a critical review, History of Science, v.33, n.4, p.375-395, 1995.

JASANOFF, S. Reconstructing the past, constructing the present: can science studies and the history of science live happily ever after? Social Studies of Science, v.30, n.4, p.621-31, 2000.

KUHN, T. S. A estrutura das revoluções científicas. São Paulo: Perspectiva, 1978.

MENDONÇA, A. Das grandes narrativas filosóficas às micro-análises historiográficas. A filosofia epistêmica e politicamente engajada de Joseph Rouse. Revista Brasileira de História da Ciência, v.6, n.2, p.196-208, 2013.

MENDONÇA, A. O legado de Thomas Kuhn após cinquenta anos. Scientiæ Studia, v.10, n.3, p.535-60, 2012.

MENDONÇA, A.; VIDEIRA, A. A. P. A assimetria entre fatos e valores: a herança de Kuhn nos Science studies. In CONDÉ, M.; PENNA-FORTE, M. (Eds.), Thomas Kuhn: A estrutura das revoluções científicas [50 anos]. Belo Horizonte: Fino Traço, 2013, p.187-210. 
ROSSI, PAOLO. La naissance de la science moderne en Europe. Paris: Seuil, 1999.

RUSSELL, COLIN. Whigs and professionals. Nature, v.308, n.5962, p.777-778, 1984.

SHAPIN, S. Nunca pura: estudos históricos de ciência como se fora produzida por pessoas com corpos, situadas no tempo, no espaço, na cultura e na sociedade e que se empenham por credibilidade e autoridade. Belo Horizonte: Fino Traço, 2013.

VIDEIRA, A. A. P. Henrique Morize e o ideal de ciência pura. Rio de Janeiro: Fundação Getúlio Vargas, 2003.

ZIMAN, J. A. Ciência na sociedade moderna. In GIL, F. (Ed.), A ciência tal qual se faz. Lisbon: Edições João Sá da Costa, 1999, p. 436-450. 